I just wish, Gentlemen, to advert shortly $\mid$ ness. On examining the body, there was to the case of stone that was operated on last no sufficient appearance of disease to account Saturday, October 17 th, which has termi- for death. 'I'he abdomen was perfectly nated fatally. It illustrates the way in healthy; the parts all natural ; the cellular which elderly persons, of a debilitated ha- membrane, about the bladder, quite loose bit, sometimes die after serious operations. and natural. There appeared to be rather This patient was sixty.seven years of age, a deficient quantity of blood in the ressels; thin, weak, and much reduced by suffer- they were, indeed, perfectly empty. This ing consequent on the disease, which had was also observed with respect to the cavilasted about three years. He came to town to have the stone removed; and the operation was performed for him, alchough the case could not but be regarder, at the time, as a very unfavourable one. Life, however, is hardly worth having in the serious state of suffering which frequently attends this complaint; so that patients may well submit to a bazardous operation for the chance of relief. This man was operated on on Saturday, and he lost, in consequence of the perineal artery being divided, somewhere between half a pint and a pint, probably 10 or 12 ounces of blood, which is not a large quantity in this operation. He was removed to bed, and I had given to him immediately two grains of crude opium. Some administer large opiates after all capital operations, but that is not my practice; I do not approve of it generally; but in the case of an enfeebled patient, like this, who had gone through a painful operation, I consi. dered the opiate might be very usefully em. ployed; and so it was, for he fell asleep soou after, and slept straight on for fourteen hours. When he awoke he expressed himself to be thirsty, and his pulse was very feeble; in fact, so feeble that it was necessary to give him wine and water. From that time; to the time of his death, which happened yesterday ('Tuesday) evening, he continued, I may aay, regularly sinking, in spite of the use of wine or brandy. His pulse was feeble, his muscles tremulous and starting, as if he had no voluntary power over them, and his voice so feeble that he could speak only in a low whisper. The tongue was rather dry, with a brown streak in the middle of it. He employed the abdominal muscles freely in respiration, and the abdomen all over was perfectly. soft and free from pain, so that there was nor a shadow of suspicion of inflammation there. The urine passed tbrough the wound, not, indeed, in the usual quantity; for you may well suppose, that the secretion of the kidneys was not so great as it would have been under other circumstances; but it passed freely. In the course of yesterday, sloughing of the back took place, at least of the back of the pelvis, on which he rested in bed. He had turned over to rest on one side, and sloughing occurred over the trochanter of that side. His state may be described as one of general sinking; a condition of pure and simple adynamia, or weakties of the heart. The kidneys were not in a healthy state; they were paler, and the glandular structure rather firmer, than natural. The mucous membrane of the excretory part had some increase of vascularity; and there was a little uric acid in a lonse form in one kidney, and a little purulent secretion in the other. The bladder was rather small. Thus, the patient has really died, as sometimes old patients do, without any reaction after the operation, and without the existence of any serious disease to account for his deatl.

\title{
ABSTRACT OF A CLINICAL LECTURE
} $\mathrm{BY}$

\section{Dr. ELLIOTSON.}

\section{PNEUMONIA.}

THE Lecturer commenced by stating to the class, that a post-mortem examination had taken place during the week, of a man who had died of pneumonia; but there was no. thing of particular interest connected with the case, and as he had just been examining a portion of the lung which had been reserved, and found that all the appearances which it had exhibited in the recent state were lost, he should not detain them long on that subject. He would, however, detail the appearances usually found after death in such cases.

There are three stages of pneumonia, the first denoted simply by great increase of redness and weight, and the expulsion of a large quantity of frothy fluid on squeezing. It is, however, the superior parts of the lung (the body being supposed to lie horizontally) which should be examined; for after a patient has been dead a considerable time, and lying on his back, the blood will naturally gravitate to the inferior part of the lungs, thus in all cases causing that portion to become very red and heavy, and to afford a frothy fluid, on compression. Now, in the present case, the lungs were much heavier than natural througloout; and, on being cut into, remained /distended, not from the air, but from the vast quantity of blood and thin fluid which they contained. It was remarked also, that the blood was not 
equally diffused throughout every part, but pulse lowered, but in a few minutes it be: particularly accumulated in' patches. 'This, came as full as before. 'The blood was al. too, is very commonly observed in inflam- lowed to flow again, the pulse was reduced, mation of various parts, and the redness in and the man laid down. Two grains of this case was so intense, that it could be ob- opium were administered, five grains of ca. served through the pleura, giving the sur- lomel ordered every two hours, and a blisface a mottled appearance. Notwithstanding the rast quantity of fluid contained in these lungs, they were quite pervious to air, and, on squeezing them, there was emitted more or less of the healthy crackling sound, similar to that which had been distingruished before death during respiration. When the crepitating sound is heard during life, it is a proof, if inflammation exists, that this is in the substance of the lungs, and in its first stage, and it is heard only in the inflamed portions. There can be no dnubt, then, that this patient died in the first stage, and death often takes place in that stage, if both lungs, or eren if ouly one of them, be inflaned throughout.

The second stage is different. The lung is still red and heavy, but does not give out a frotby fluid on compression, as in the first. The air cells are become impervious to air; there is not any crackling sound on squeezing the lung after death; and if the stethoscope be applied duing life, respiration cannot be heard at all in the inflamed portion, and on striking the chest, only a dead sound is heard on the inflamed spot. 'The lung has become solid, or, in other words, hepatization has taken place.

In the third stage, the colour of the lung is altered; we have no longer the dark-red appeannce exhibited in the two former stages, but it is now of a yellowish or straw colour, and is still firm, heavy, and impervious to air ; respiration is not heard before, nor any crackling after death in the part afiected, and this contains an amber-coloured fuid, in short, suppuration has taken place. We do not generally find the pus diffused throughout the lung, but in patches; neither is it collected in a mass, for nothing is more rare than to find abscesses in the lungs from simple suppuration. 'The abscesses of this olgan are the result of tubercles, but $I$ do not remember to have seen simple infammation induce abscesses abore once or twice in my life. It is not, howerer, necessary for inflammation to go sa fai as this to produce death; the patient may die in the first stage, and $I$ have before said, that such was the case in the present instance. The treatment was not commenced here until five hours before death, and I am satisfied that the case must have been hopeless for scveral days previously. The poor creature was picked up in the streets, and sent to the hospitsl by the Lord Mayor, in the cold fit of azue, with general dropsy, and the peripneumonia. I ordered him to be placed upright, and bled to fainting; this was done, the

1 have been asked by a gentleman (and very properly), if I thought that in this instance, the bleeding at all hastened the man's death? Did I believe such to be the case, I would not hesitate to say so; but I do not think it did, and I wll tell you my reasons. In one or two instances in my life, where symptoms have been very urgent, and vigorous measures therefore requisite, I have reflected upon myself afterwards, under an idea that the event lad been hastened by the treatment, although per. fectly convinced, that the parient could not otherwise have recovered; but, then, as in cases of death from hamorrhage, the pulse became small, weak, and fluttering, after the bleeding, that is, became decidedly worse, from the abstraction of blood; but in this case the patient was seen in the evening, about an hour before be died, when the pulse was not weak and rapid, but, on the contrary, more ample, and less frequent; the pain in the side was relieved, and the breathing much easier. When the pulse becomes slower and more soft and ample after venesection, it proves that the bleeding has been of service. The man died rather suddenly, and had the treatment been com. menced a few days earlier, I have no doubt the patient might have been saved, but there was no time for improvement; the blister could not rise, nor the mercury affect the mouth. I now proceed to make a few more remarks on

\section{THE TREATMENT OF RHEUMATISM.}

In my last lecture, 1 mentioned my conviction, that active rheumatism, whether acute or chronic, should be treated by local or general bleeding, and colchicum, or mercury, internally, with lotions to the affected parts when the heat is extreme; and that the only difference in the treatment of acute and chronic rheumatism is, that in the former we shculd use bold and active measures; in the latter, where we cannot expect the disease to yield rapidy, our treatment should be, not bold, but peisever. ing. In all diseases where we have carefully made our diarnosis, not only as to the hind, but the variety of the disease, and well weighed the patient's powers, our business is to be vigorous, without rashness, in acute, and persevering in chronic affections.

Now in the opposite cases of rheumatism, where there is not any increase of tempera. ture, nor any additional pain from the ap. plication of heat, but, on the contrars, re. 
liff from it, colchicum and the abstraction saponis cruribus bene infricandum bis die. of blood would be useless; we must then employ internal and external stimulants, as guiscum, ammonia, steel, fermented liquors, the hot bath, and rarious irritants. WVe shall find a combination of guiacum with anmonia, as in the tinctura guiaci ammoniata, very rseful. The dose is cf course raiable in different persons, generally from one to two drachns may be given; but three, and even six drachms, I have known borne. However, in doses so large as this last, it will often cause nausea, and otherwise disturb the stomach of some persons, and should be taken diluted with barley water; yet l have known these dose not only borne, but required by the extreme coldness of some persons in the disease. Iron also will be found of great benefit. The ammoniated tincture is rery gcod, but requires the dose to be increased, often from 60 to above 100 drops. It has been suppozed by some perBons, that the carbonate is the best preparation of this metal in rheumatism; but in $\mathrm{my}$ own fractice, Thave found the sulphate succred fully as well, and of this also, the dose is rariable; we should, therefore, in inaliing use of either of these nedicines, as in so many others, feel our way, beginning with small doses, and gradually increasing, as we find the stumach will bear, and the disease demand it. This is also proper for another reason; we shall find with most medicines, that they lose their effects by continuance, and $a$ large dose is required at last to effect what a small dose was effecting previously. Iron is often preferable to ammonia, \&xc., especially when there is great dubility, not because the disease is chronic rheumatism, but because the disease is of a form that requires stimulants, on account of the pain being increased by cold and relieved by warmth. It is here, too, that the warmbath is so useful, and I ondered the first pa. tient, whose case I will mention, the slipper bath daily:-

Elizabith Ferry, wtat. 53, admilted October $29 \mathrm{~h}$, says, that about seven weeks ago she became very wet and cold during a jour. ney on the top of a calch, and immediately after was altacked witi severe pain in the limbs, and gradually lost the use of her lower extremities until a week after, when they had become quite motionless; cannot move the toes at all, but the loss of power does not appear to extend higher than the bnets, and there is no loss of sensation. Has frequent cold chills; thirst; tongue clean in the middle, red at the tip and eitges. When frst attacked, had pain also in the back and between the shoulders, and then perspired a good deal, but does not now. Pulse 150, soft, and rather full; urine high-colonred; tongue whitish ; pain relieved by warmth. Semicupium calidum quotidie linimentum Ferri sulphatis, gr. v. ter quotidie. Dieta communis; porter a pint daily.

Nov. 2. Pain in lower limbs to-day is diminished, but so bad during the night as to prevent sleep; cannot yet move the toes. Complains now of severe pain in the right band; none in the back or botween shoulders. Pulse 126; bowels not open since admis. sion until last erenirg, when she took a dose mistura sennx compos., and she has since had four stools. Tongue clean; pain always worse at night.

3. Not more vise of limbs; complains of much pain in ancles; bowels open, pulse 132. Pain severe during the night, but now better. Ferri sulph.gr. x. ter die. This plon was steadily contimued, and she is now free from pain, and moves her limbs, and will probably soon recover completely. Good nourishment also is proper, therefore $I$ put her on house diet, and, in addition, ordered a pint of porter daily, which will be in. creased if $I$ find she requires it. Stimulating. liniments are in such cases very beneficial, and one of the best is the linimentum sina. pis. It is in cases of rheumatism attended by coldness, or relieved by heat, that acupuncturation is beneficial, excepting when a joint is the part affected; for of course you would not think of introlucing a needio into a joint, at least I should not do so, though some among the firench say they plunge it almost every where. There is a second case admitted on Thursday last in King's Warl, similar in its nature to the former.

Samuel Row, thirty-one ycars of age, stated, on admission, that he had been ll three months; lie complained of pain extending down the course of the sciatic nerve, accompanied by a scysation of cold, and much relieved by the application of warmti. The pain is cheily in the calf of the leg, and in the hip: not extending to the ancle; and is increased by motion. Had been stmding in the water for some hours previous to its comiug on. Bowels open daily; pulse 90. Acuiruncture: two needles to be introduced into the hip, and two in the calf of the leg.

Thinking this a case for acupuncture, I ordertd it to be employed, but it could not be done on that day; and the next, when the dresser came to iniroduce the neodlcs, the pain lad entirely censed. Now here it was very evident that the cessation of pain har been caused by alarm, at the idea of having needles introduced into the shin; but a similar occurrence may happen in the employment of any kind of medicine. For instance, if a person believe he has taken opium, the effect of sleep will be sometimes induced, although the substance given may have been perfectly inert, as bread-pill. I have known a copious eracuation take place 
from the bowels from alarm, at the idea of an enema. It might be objected, that had these medicines been administered, the event would have been supposed to result from their action; but yet no one would attempt to dispute the fact, that opium has a soporific power, nor that salts can purge; therefore what happened in this man, is no argument against the power of acupuncture; no argument that, in every case where acupuncture appears useful, the benefit is acci. dental. It had been applied before my arrival, according to my prescription, notwithstanding the loss of pain; but thinking its use conld afford no ground for interference, under these circumstances I directed it to be omitted; and the next day, when the eflects of fear had subsided, the pain returned; I therefore again ordered it to be applied, and the patient is now considerably better, though still lame. I mentioned in my last lecture, that the length of time, before any perceptible improvement takes place, is variable; it is sometimes evident before the needles are removed, most frequently after the second application, and sometimes not until after repeated trials.

There is also a patient, in George's Ward, formerly treated for me by Dr. Roots, whose rheumatism is of the cold character, and is subsiding under the use of stimtilants.

William F. Searle, a fisherman at Billinsgate, admitted on the 17 th of September, stated that during the last five or six months, he had had three or four attacks of acute rheumatism affecting chiefly the ancles, and attended by swelling and redness; for the last three months it has assumed a more chronic form, and he now complains of great pain in his loins, and in the feet and ancles, when he first attempts to stand or walk. The pain in the loins is much increased; on rising from a low seat, or on turning over in his bed, there is much pain in the arm and shoulder, and he complains of a painful stiffness in the thumb and fore-finger of either hand; thinks the pain less when warm; has frequent cramp in the calves of the legs, and occasional pain of the head; has drunk hard; tongue whitish; is uneasy after food, though his appetite is good; bowels open; urine high-coloured; pulse 84, weak, al. though the has been taking porter and brandy to-day. Ordered a warm-bath daily.

Ammoniated tincture of guiacum, two drachms ;

Wine of tarturised antimony, half a drachm every six hours. Milk diet.

On my return to town, I found him lying in bed upon his back, unable to move his lower extremities, even his toes or his right shoulder. These parts were all very cold, and in great pain, which was relieved by warmth, and he complained of great debility and depression of spirits. I continued the stimulating plan commenced by Dr. Roots, and ordered acupuncture. Two needles to be introduced in to the right deltoid, and to remain two hours daily. Since which he has been gradually getting better; is now able to walk about the ward on crutches, and improves daily. Here I employed acupuncture in the shoulder with great relief. He then caught cold from a dranght from the window behind his bed, and the symptoms returned. 1 had recourse to it a second time with success; afterwards it attacked the ancles, where, of course, I cannot use it; he is going on extremely well, but perseverance is required, and I have no doubt he will ultimately recover. During the ex. hibition of stimulants, the character of rheu. matism will sometimes change from the cold to the inflammatory type. It is needless to say, we must then alter our treatment; so also the inflammatory kind may change to the cold, and then too it would be absurd to continue the same remedies. Mercury is often useful in this inactive form of the disease, as well as almost always in the more active kind; bark also is very proper here, though inferior to iron; but there is one period of rheumatism, in which it is much move serviceable; namely, as soon as the active stage is over, to prevent the inactive stage from being established; but, in mere chronic rheumatism, iron is by far the more preferable. Dr. Haygarth is often adduced as authority for the exhibition of bark in active rheumatism, but he did not give it till he had freely purged and sweated, and thus overcome the activity of the disease; of course where bark is useful, quinine will generally be still more so. As for narcotics, the best means we can employ for relieving pain, when it arises from infiammation, is the application of leeches, and other means, to produce this effect, by subduing the inflammatory action; but there may be no barm in administering, at the same time, opium, belladonna, or strammonium, if the pain is very severe, or out of proportion to the inflammation. 'The pain of cold, in active rheumatism, is exactly adapted for narcotics ; opium, strammonium, and bella. donna, are the most to be relied on; but the two latter do not produce torpor of the bowels, and are, therefore, of ten preferable to opium in moderate doses. They oniy. produce sleep in a negative manner by relieving pain, but for this purpose are quite equal to opium, and in one form of rheuma. tism, I think superior. That form is the intermittent or remittent; the pain perhaps attacking one side of the face only, and generally coming on in the afternoon; in such cases the sulphate of quinine, and other preparations of bark, and the arsenical solu- 
tion, are of great service ; but especially a narcotic, given just as the pain is expected. Belladonna, or strammonium, are admirable here. There are two cases of this kind now under my care. The first is that of a young man in Henry's Ward, aged 20, ad. mitted on the 29 th of October, with pain in the right half of the head extending downwards to the face and neck, also pains in the limbs. It always becomes worse at six or seren o'clock in the evening, but he is never entirely free from pain. Sweats much.

I ordered one grain of the extract of strammonium to be given at five in the afternoon, and to be repeated every three hours, until the pain was relieved; also lalf an ounce of castor oil immediately.

0 the 31 st the pain continued, but with some mitigation, and the exacerbation did not occur until much later in the evening. I then ordered the dose to be increased to two yrains every three hours, whenever the pain should be severe. He has since required the pills frequently, and had a return of pain, though much slighter, at four o'clock this morving, when he took a pill, and slept until eleven, since which he has been entirely free from pain. The pills have once induced delirium, and were then omitted until the recurrence of the pain. You will observe that the exacerbation of pain, which at first took place between six and seven in the afternoon, has (whilst be. coming slighter in degree) come on also later and later, until now it was protracted until four in the morning. Strammonium commonly produces great thirst and dimness of sight; this is of no great consequence; but when the patient complains of giddiness also, or confusion of head, it is as well not to repeat the dose until these effects have subsided. These means will often subdue the disease at once, but sometimes perseverance is necessary. Frequenily when the pain does return, it comes on later and later (as in this instance), in the same manner as ague, when this disease is subsiding.

We should always pay particular attention to any pain within the head, or any in. tammatory marks attending the external pain, although satisfied that the latter is rheumatism. 'Throbbing, heat, and swelling of the extermal parts, or heaviness, gid. diness, and sense of tightness, may demand bleeding, general or local; and should these be considerable, narcotics may be improper; if not considerable, these antiphlogistic measures may be used in conjunction with them. Now this was the case with a man in King's IVard.

John Franks, about twenty years of age, who bad been a patient of Mr. Green in King's Ward, complained, on the z7th of Tctober, of pains at the right side of the ead, increased by cold, extending down to the face and neck. 'The attack came on every afternoon at four o'clock, and lasted about six hours; he was then free from pain until four o'clock the next morning, when it returned, and continued about the same time as before. As the disease assumed an intermittent type, I ordered ten grains of quinine to be given at three P.M., and repeated every eight hours. 'Two days after, finding him not much relieved, I ordered two grains of the extract of strammonium to be taken just before the pain was expected, and repeated every three hours, in addition to the quinine. This was continued for a day or two, when I found some inflammatory symptoms; namely, throbbing, and increased heat. I therefore ordered twenty leeches to the head, and the quinine to be continued as before; he has since been going on extremely well, and is now much better, though not yet perfectly recovered. When rheumatism affects the head, the pain generally extends from the head to the face, and back of the neck; the scalp is tender, rheumatism often co-exists in the extremities, and the pain frequently is remittent, if not intermittent; the attack occurring towards the close of the day, and usually confined to one side; but though external, it is often attended by congestion, or determination of blood within the cranium, and this requires to be treated, independently of the rheumatism, in the ordinary way. Just as in these two cases, I frequently employ strammonium; half a grain, or even so much as two, or three, grains, should be given, just before the pain is expected, and repeated aboul every three hours till relief is obtained, or the head affected by the remedy; and on the recurrence of the pain, it should be repeated in the same wry.

\section{PRACTICALSTRICTURES ON PUER. PERAL FEVER.}

\section{By John Alexander, M.D., Mancliester.}

"It is quite time that physic should cease to assert, and commence to prove; that it should re-examine what it has hitherto believed, together with its ground of bulief, and not be content, in these days of a better philosophy, with its ancient dogmas, or with that which it acts on from habit, not from conviction."-Macculloch's Essay on Malaria, p. 476.

IN the earlier and darker ages, medicine had but few followers, and those few knew little of the art they professed. The irradiating light of knowledge, however, gradually diffused itself, and, despite of the bar 